\title{
Dielectric elastomer materials for actuators and energy harvesting
}

\author{
Dorina M. Opris, ${ }^{\mathrm{a}}$ Martin Molberg, ${ }^{\mathrm{a}}$ Frank Nüesch, ${ }^{\mathrm{a}}$ Christiane Löwe, ${ }^{\mathrm{a}}$ \\ Christian Walder, ${ }^{a}$ Beatrice Fischer ${ }^{a}$ \\ ${ }^{a}$ Empa, Swiss Federal Laboratories for Materials Science and Technology, Functional Polymers \\ Laboratory, Ueberlandstrasse 129 \\ CH-8600, Dübendorf, Switzerland
}

\begin{abstract}
The success of dielectric elastomer materials in actuator technology as well as in energy harvesting is much influenced by the material parameters, e.g. breakdown field, dielectric constant, and elastic modulus which have a direct impact on the driving voltage. By increasing the dielectric constant of a material the activation voltage can be decreased, however this increase is very often associated with a decrease in the breakdown field. In this proceeding, dielectric elastomer materials based on polydimethylsiloxanes with increased strain at break and high breakdown fields are presented.
\end{abstract}

Keywords: dielectric elastomer actuators, elastomers, dielectric constant, breakdown field

\section{INTRODUCTION}

The unusual properties of polydimethylsiloxanes (PDMS), such as good thermal stability, low viscoelastic losses, high gas permeability, and good dielectric properties are due to their semi-inorganic composition. Although the mechanical properties of silicones do not change over a wide temperature range, they suffer from a low strain at break and low tear strength which makes the handling of the thin films quite difficult. Silicone's mechanical properties can be improved by mechanically mixing silica ${ }^{[1]}$ or titanium dioxide particles. ${ }^{[2]}$ The in-situ generation of silica or titanium dioxide particles was used to reinforce silicone elastomers. ${ }^{[3]}$ Particles present during the cross-linking reaction can interact directly with the other components or influence the reaction indirectly, thus changing the properties of the material. Silica particles have a hydrophilic surface, and interact very strongly with the silicone. In order to avoid this, the particles were passivated prior adding to the matrix, by using a low molecular weight plasticizer or by reacting it with an organosilane or organosiloxane. ${ }^{[4]}$ Although these approaches provided fillers with improved reinforcing properties, it requires additional manufacturing steps. Silicone elastomers with high strain at break and high tear strength are important in dielectric elastomer actuators (DEA). ${ }^{[5]}$

Beside their use as actuators, dielectric elastomers can be used to generate electrical energy when mechanical work is done against the electric field. An external mechanical force is used to stretch the dielectric elastomer, followed by charging of the stretched film. It is thereafter allowed to contract by using the elastic forces. Thus mechanical forces are working against the electric field pressure and the electrical energy increases. A working cycle of a DE generator comprises the steps: a) stretching in the area, b) charging, c) mechanical relaxation, and d) energy harvesting. ${ }^{[6]}$ Light elastomer materials with high strain at break, high dielectric constant, and high breakdown fields are interesting candidates for generator applications.

In the present investigation, poly(divinyl benzene) PDVB particles prepared by using miniemulsion polymerization were used to improve the mechanical properties of the silicone. Defined amounts of particles were mixed into a hydroxyl endfunctionalized silicone which was subsequently cross-linked. The resulting composites were characterized regarding their mechanical, electrical, and electromechanical properties.

Electroactive Polymer Actuators and Devices (EAPAD) 2011, edited by Yoseph Bar-Cohen, Federico Carpi, Proc. of SPIE Vol. 7976, 79760G · (C) 2011 SPIE · CCC code: 0277-786X/11/\$18 - doi: 10.1117/12.880358 


\section{Materials}

Linear hydroxyl end functionalized silicone (PDMS) $\left(\mathrm{M}_{\mathrm{w}}=139^{\prime} 000\right)$ by $\mathrm{ABCR}$ was used to produce polymer films, $\mathrm{A} 7$ by Altropol Kunststoffe was used as cross-linker, and dibutyltindilaurate (Sn cat) from Aldrich was used as catalyst. Divinyl benzene (DVB) $80 \%$ mixture of isomers, Tween 80 , and hexadecane were purchased from Aldrich, AIBN from Fluka. The cross-linker A7 was investigated by GPC and it was found that it contains a component with $\mathrm{M}_{\mathrm{w}}=7600$ $\mathrm{g} / \mathrm{mol}(46 \%)$ and two lower molecular weight components $\mathrm{M}_{\mathrm{w}}=826(32 \%)$ and $\mathrm{M}_{\mathrm{w}}=291(22 \%)$.

\section{Methods}

Dielectric constant measurements were done in the frequency range of $20 \mathrm{~Hz}$ to $1 \mathrm{MHz}$ using an HP 4284A LCR meter. The amplitude of the probing ac electric signal applied to the samples was $1 \mathrm{~V}$. The dielectric constant was determined from the capacitance $C=\varepsilon \varepsilon_{0} A / d$, where $A$ is the electrode area, $d$ is the thickness of the capacitor, and $\varepsilon_{0}$ is the vacuum permittivity. The samples were squeezed between two electrodes (diameter of $5 \mathrm{~mm}$ ).

The tensile tests were performed using a Zwick Z010 tensile test machine with a crosshead speed of $500 \mathrm{~mm} / \mathrm{min}$. Tensile test specimens with a gauge width of $3 \mathrm{~mm}$ and a gauge length of $30 \mathrm{~mm}$ were prepared by die cutting. The strain was determined by optical measurement (Zwick video extensometer 066975) of the displacement of two marker points placed along the waist of the tensile test bar.

Actuator tests were performed using circular membrane actuators, for which the films were $30 \%$ prestrained and fixed between two circular frames. Circular electrodes $(8 \mathrm{~mm}$ diameter $)$ of carbon black powder were applied to each side of the film. A FUG HCL-35-12500 high voltage source served as power supply for actuator tests. The voltage was increased by about $500 \mathrm{~V}$ every $15 \mathrm{~s}$. The actuation strain was measured optically as the extension of the diameter of the electrode area via a digital camera, using an edge detection tool of a LabView program to detect the boundary between the black electrode area and brighter (greenish) film.

Miniemulsion polymerizations: To a solution of Tween $80(0.1 \mathrm{~g})$ in water $(18 \mathrm{~g})$, hexadecane $(0.37 \mathrm{~g})$, divinylbenzene (4 g), and AIBN (0.1 g) were added and stirred together for $1 \mathrm{~h}$. The resulting emulsion was then miniemulsified with a Sonics $750 \mathrm{~W}$ Digital sonifier (13 $\mathrm{mm}$ horn) at amplitude of $70 \%$ for $3 \mathrm{~min}$. while being cooled with an ice bath. The miniemulsions were subsequently transferred and stirred in an oil bath at $75^{\circ} \mathrm{C}$ overnight. All the miniemulsions were prepared with deionized water. The reaction mixture was stirred overnight and let to cool down to room temperature. They were dried in a vacuum oven at $100{ }^{\circ} \mathrm{C}$ and then ball milled for $10 \mathrm{~min}$. at $20 \mathrm{~Hz}$ (ball $\varnothing=8 \mathrm{~mm}$ ).

Synthesis of Composites A: Appropriate amounts of PDVB were added to a solution of functional PDMS oligomer in toluene ( $25 \mathrm{wt} . \%)$ to obtain $5,10,15$, or $20 \mathrm{wt} . \%$ of particles in oligomer and mixed by using a three roll mill (Bühler) to obtain homogeneous dispersions. Thereafter Neukasil A7 cross-linker and Sn cat $50 \%$ solution in toluene were added to the dispersions (Table 1). The proportion between functional PDMS oligomer and Neukasil A was kept constant (1:1). The mixtures were sonicated for $1 \mathrm{~min}$ in a water bath to remove air bubbles. Free-standing films were prepared by using a Zehntner ZUA 2000 instrument where toluene evaporated during cross-linking.

Table 1. Synthesis of composites A containing different amounts of PDVB particles.

\begin{tabular}{ccccc}
\hline Sample & $\begin{array}{c}\text { PDVB } \\
(\mathrm{g})\end{array}$ & $\begin{array}{c}\text { Silicone } \\
(\mathrm{g})\end{array}$ & $\begin{array}{c}\text { Neukasil A } \\
(\mathrm{g})\end{array}$ & $\begin{array}{c}\text { Sn cat }(50 \%) \\
\text { in tol }(\mu \mathrm{l})\end{array}$ \\
\hline $\mathbf{A}_{\mathbf{0}}$ & - & 5 & 5 & 400 \\
$\mathbf{A}_{\mathbf{5}}$ & 0.5 & 4.75 & 4.75 & 400 \\
$\mathbf{A}_{\mathbf{1 0}}$ & 1 & 4.5 & 4.5 & 400 \\
$\mathbf{A}_{\mathbf{1 5}}$ & 1.5 & 4.25 & 4.25 & 400 \\
$\mathbf{A}_{\mathbf{2 0}}$ & 2 & 4 & 4 & 400 \\
\hline
\end{tabular}

\section{Results and discussions}

Miniemulsion polymerization technique was used to prepare PDVB particles. Water was used as continuous phase and divinylbenzene as both reactant and disperse phase. The particles were stabilized by a surfactant (Tween 80 ). AIBN was used to initiate the polymerization. The PDVB particles were dried in vacuum oven and then ball milled. 
In the present work a hydroxyl end-functionalized silicone $\left(\mathrm{M}_{\mathrm{w}}=139^{\prime} 000 \mathrm{~g} / \mathrm{mol}\right)$ was used as matrix and cross-linked according to Scheme 1.<smiles>C[Si](C)(O)O[Si](C)(C)O[InH]</smiles>

Scheme 1. Cross-linking reaction used for the formation of room temperature vulcanized silicone rubber.

The weight ratio between hydroxyl end-functionalized silicone and cross-linker was kept constant (1:1) for all formulations. Four series of composites, each containing 5, 10, 15, and $20 \mathrm{wt} \%$ of PDVB particles were prepared as described in the experimental part. In order to reduce the viscosity of the system and to facilitate better mixing, toluene was used. The cured reaction was performed at room temperature under ambient conditions by using Neukasil A as cross-linker and Sn cat. The films were let undisturbed for at least one week. The electrical, mechanical, and electromechanical properties of the prepared composites were investigated as presented in the following sections.

\section{Mechanical properties}

The mechanical properties of the matrix as well as of the composites were studied by tensile tests. The stress-strain curves averaged from several independent tests are shown in Figures 1 to 5. A great advantage of the composites is the high strain at break which increases with increasing the amount of PDVB particles compared to the matrix. It increases from $250 \%$ for the matrix to $556 \%$ for composite $\mathbf{A}_{15}$. A farther increase of the amount of filler has a negative impact on the elongation at break. Thin films of such composites can be easily handled and removed from the substrate. This is due to enhanced fracture toughness of the composites as compared to the silicone matrix. The increase of fracture resistance by small particle fillers ${ }^{[7]}$ as silica or titania is a well known effect for elastomer materials. ${ }^{[8]}$ The advantage of using PDVB as filler to replace the silica or titania as silicone reinforces are: its low density, easy of synthesis in one single step starting from inexpensive materials.

Table 2 summarizes the moduli at three different strains, $F_{\max }$, average elongation at break, and maximum elongation at break for the composites as well as for the matrix.

Table 2. Elastic moduli of the matrix and of the composites with different amounts of PDVB particles at three strain levels, $\mathrm{F}_{\max }$, and maximum elongation at break.

\begin{tabular}{cccccc}
\hline Sample & $\begin{array}{c}\text { Modulus } \\
{[10 \%]} \\
{[\mathrm{kPa}]}\end{array}$ & $\begin{array}{c}\text { Modulus } \\
{[20 \%]} \\
{[\mathrm{kPa}]}\end{array}$ & $\begin{array}{c}\text { Modulus } \\
{[100 \%]} \\
{[\mathrm{kPa}]}\end{array}$ & $\begin{array}{c}\mathrm{F}_{\max } \\
{\left[\mathrm{N} / \mathrm{mm}^{2}\right]}\end{array}$ & $\begin{array}{c}\text { Elong. } \\
{[\%]}\end{array}$ \\
\hline $\mathbf{A}_{\mathbf{0}}$ & 192 & 152 & 81 & 0.41 & 252 \\
$\mathbf{A}_{\mathbf{5}}$ & 246 & 192 & 98 & 0.47 & 510 \\
$\mathbf{A}_{\mathbf{1 0}}$ & 234 & 189 & 105 & 0.59 & 509 \\
$\mathbf{A}_{\mathbf{1 5}}$ & 250 & 205 & 119 & 0.83 & 556 \\
$\mathbf{A}_{\mathbf{2 0}}$ & 256 & 210 & 125 & 0.68 & 453 \\
\hline
\end{tabular}




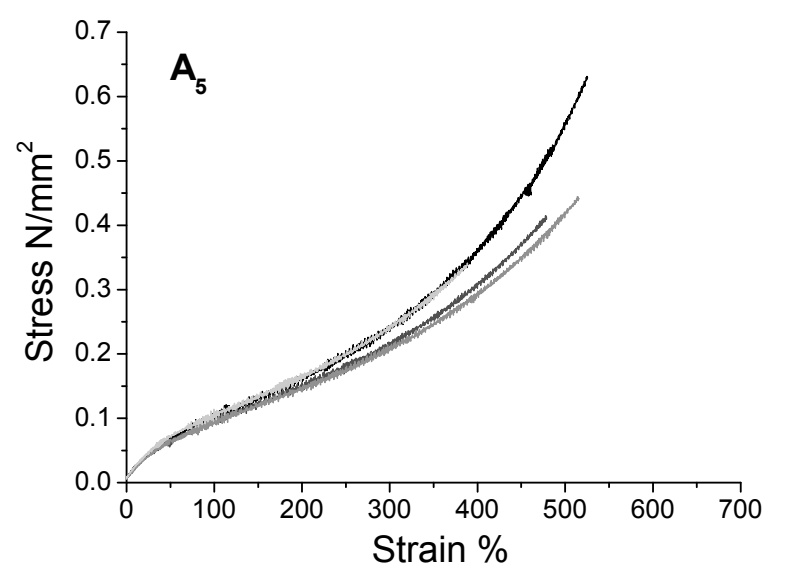

Figure 1. Stress-strain curves for the composite $\mathbf{A}_{\mathbf{5}}$ obtained from the standard tensile tests at $500 \mathrm{~mm} / \mathrm{min}$.

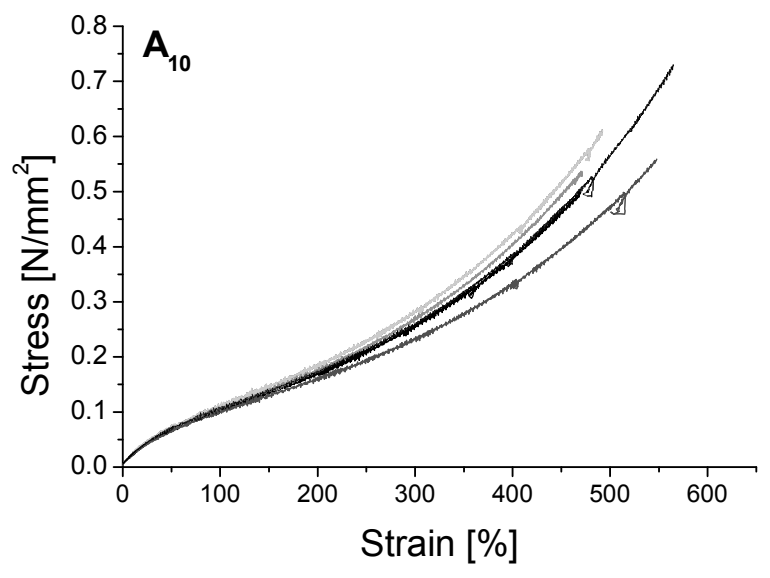

Figure 2. Stress-strain curves for the composite $\mathbf{A}_{\mathbf{1 0}}$ obtained from the standard tensile tests at $500 \mathrm{~mm} / \mathrm{min}$.

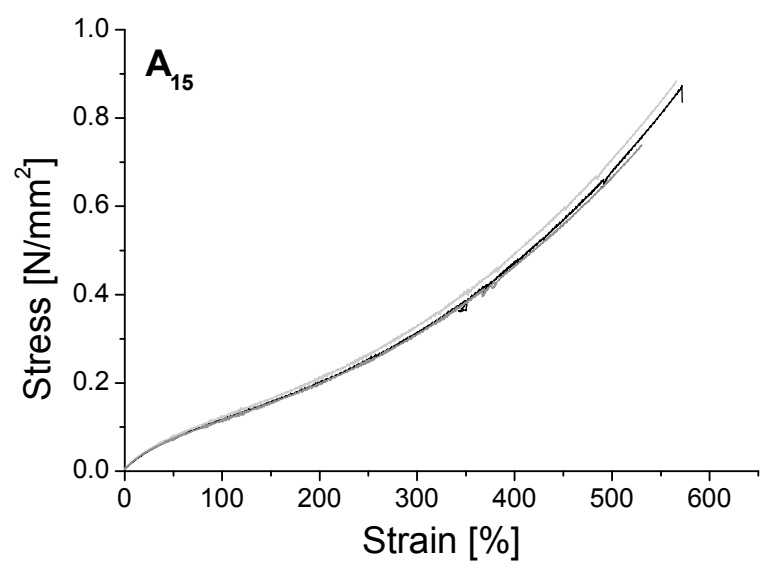

Figure 3. Stress-strain curves for the composite $\mathbf{A}_{\mathbf{1 5}}$ obtained from the standard tensile tests at $500 \mathrm{~mm} / \mathrm{min}$. 


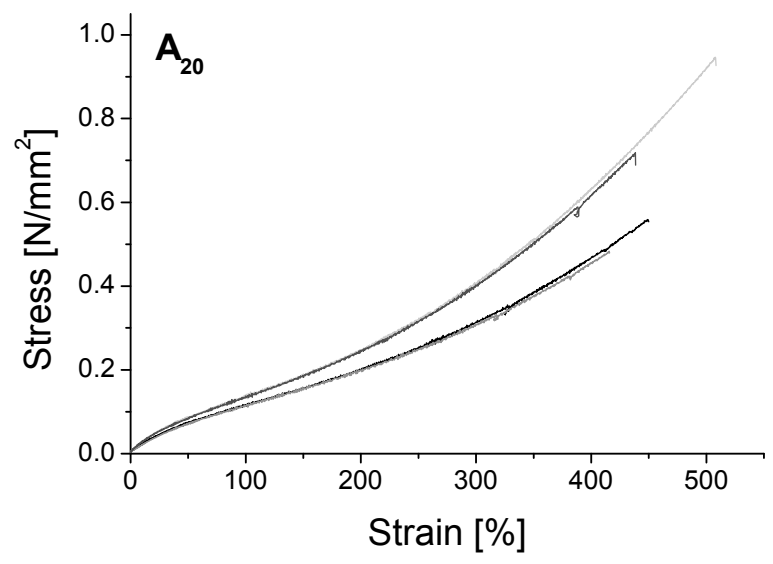

Figure 4. Stress-strain curves for the composite $\mathbf{A}_{\mathbf{2 0}}$ obtained from the standard tensile tests at $500 \mathrm{~mm} / \mathrm{min}$.

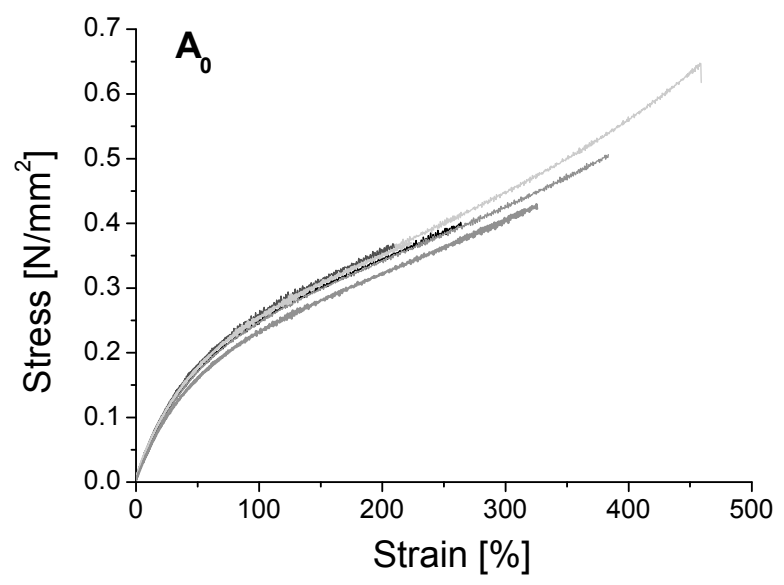

Figure 5. Stress-strain curves for the composite $\mathbf{A}_{\mathbf{0}}$ obtained from the standard tensile tests at $500 \mathrm{~mm} / \mathrm{min}$.

The elastic moduli increases slightly with increasing amount of filler at all strain levels, e.g. from $152 \%$ for the matrix to $210 \%$ for the composite containing $20 \mathrm{wt} \%$ PDVB filler at $20 \%$ strain.

\section{Dielectric properties}

The dielectric properties of the composites with different amounts of PDVB filler were investigated at room temperature as a function of frequency (Figures 6, 7, 8). The dielectric constant slightly increases with the amount of filler from 2.7 for silicone to 2.8 for $\mathbf{A}_{20}$ which may be caused by interface polarization. 


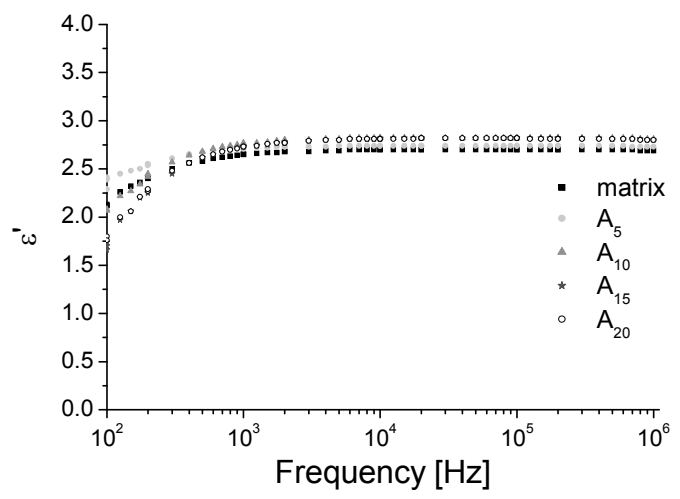

Figure 6. Dielectric constant of the composites containing PDVB filler and of the matrix as a function of frequency at room temperature.

The dielectric loss is quite low at high frequencies, less then 0.005 and increases at lower frequencies up to 0.5 (Figure 7). The conductivity increases slightly with increasing amount of filler from $1.4 \times 10^{-9}\left(\mathrm{Ohm}^{*} \mathrm{~m}\right)^{-1}$ for the matrix to $4.1 \times$ $10^{-9}(\mathrm{Ohm} * \mathrm{~m})^{-1}$ for composite $\mathbf{A}_{\mathbf{2 0}}$.

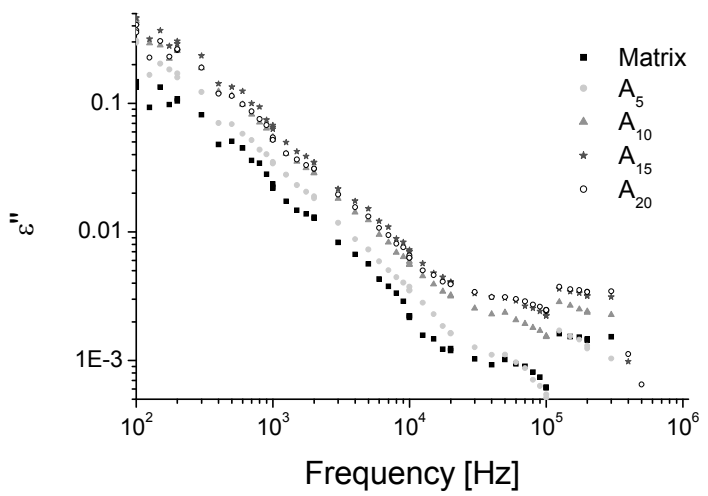

Figure 7. Dielectric loss of the composites containing PDVB filler and of the matrix as a function of frequency at room temperature.

\section{Electromechanical properties}

The determined actuation strain for the composites and matrix are shown in Figure 8 as a function of electric field strength. The composites were $30 \%$ prestrained, while for the matrix a $20 \%$ prestrain was used. The strain at a certain electric field is decreased for all composites. For example at $30 \mathrm{~V} / \mu \mathrm{m}$ a $11 \%$ strain was measured for the matrix, while for the composites a 5.6\% strain was measured at the same electric field. The breakdown field as well as the maximum strain at breakdown is somehow increased for the composites. Thus, composite $\mathbf{A}_{\mathbf{2 0}}$ shows the highest breakdown field of $47 \mathrm{~V} / \mu \mathrm{m}$ and the highest lateral strain of $22 \%$. 


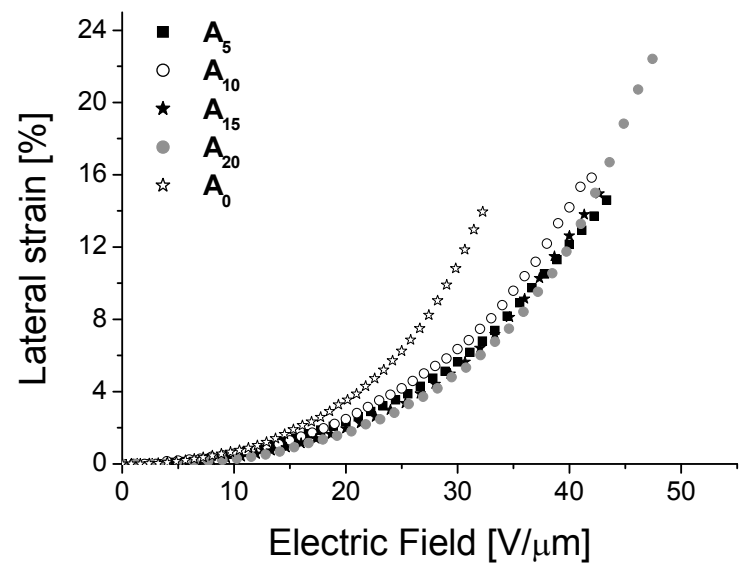

Figure 8. Lateral strain of membrane actuators for the matrix (20\% prestrain) and composites containing different amount of PDVB particles as a function of applied voltage. Each curve represents the average of two different actuator devices.

Actuator performance is characterized not only by the strain at a certain voltage, but also by the actuator energy density which can be calculated according to equation (1):

$$
U_{e l}=\frac{1}{2} \varepsilon_{0} \varepsilon E_{b r}^{2}
$$

A higher electric energy may lead to a higher mechanical work output.

The values calculated for the energy density of the actuators made of composites and of the matrix are summarized in Table 3 together with the dielectric constant and the breakdown field.

Table 3. Dielectric constant, breakdown field, and energy density of composites containing different amounts of filler as well as of the silicone matrix.

\begin{tabular}{ccccc}
\hline $\begin{array}{c}\text { Filler } \\
{[\%]}\end{array}$ & $\varepsilon^{\prime}$ & $\begin{array}{c}\mathrm{E}_{\mathrm{br}} \\
{[\mathrm{V} / \mu \mathrm{m}]}\end{array}$ & $\begin{array}{c}\mathrm{U}_{\mathrm{el}} \\
{\left[\mathrm{mJ} / \mathrm{cm}^{3}\right]}\end{array}$ & $\begin{array}{c}\Delta \mathrm{W}_{\max } / \mathrm{V} \\
{\left[\mathrm{mJ} / \mathrm{cm}^{3}\right]}\end{array}$ \\
\hline $\mathbf{A}_{\mathbf{0}}$ & 2.7 & 32 & 12 & 18.9 \\
$\mathbf{A}_{\mathbf{5}}$ & 2.74 & 42 & 21 & 35.8 \\
$\mathbf{A}_{\mathbf{1 0}}$ & 2.8 & 42.2 & 22 & 38.6 \\
$\mathbf{A}_{\mathbf{1 5}}$ & 2.8 & 43.3 & 23 & 39.6 \\
$\mathbf{A}_{\mathbf{2 0}}$ & 2.8 & 47.4 & 27 & 60.5 \\
\hline
\end{tabular}

The new composite $\mathbf{A}_{\mathbf{2 0}}$ has a higher breakdown field and a two-fold increase in the energy density as compared to the silicone matrix.

The electrical energy gained when the actuator is used in the generator mode is given by the difference in the electrostatic energy, and can be estimated as follows ${ }^{[7]}$ :

$\Delta W=\frac{1}{2} \frac{Q^{2}}{\varepsilon \varepsilon_{0}} \frac{d_{0}}{A_{0}}\left(1-\frac{1}{\lambda_{x}^{2}}\right)$

with $\lambda$ being the strain at break. The maximum charge density is limited by the breakdown strength:

$Q_{\max }=\varepsilon \varepsilon_{0} A_{0} E_{\max }$

Thus the specific energy per unit volume 
$\frac{\Delta W_{\max }}{V}=\frac{1}{2} \varepsilon \varepsilon_{0} E_{\max }^{2}\left(1-\frac{1}{\left(s_{\max }+1\right)^{2}}\right)$

The calculated electrical energy that can be gained during one working cycle for the materials prepared in this work was calculated and summarized in Table 3. The best value for the energy gained was found for composite $\mathbf{A}_{\mathbf{2 0}}$, which exhibited a three fold increase compared to silicone matrix. Further work is needed to determine experimentally the energy difference of such materials.

\section{Conclusions}

Elastomeric networks of polydimethylsiloxane were reinforced with PDVB particles. Composites containing different amounts of filler were dispersed into a hydroxyl end-functional silicone that was subsequently end-linked. The resulting composites were characterized with regard to their mechanical properties in elongation, dielectric and electromechanical properties. It was found that the new prepared composites have increased strain at break, increased breakdown field, and increased energy density compare to the matrix.

\section{Acknowledgements}

We gratefully acknowledge to Dr. Gabor Kovacs for providing us with the infrastructure for the actuator measurements and to EMPA for financial support.

\section{REFERENCES}

[1] Dewimille, L., Bresson, B., Bokobza, L., Polymer, 46, 4135, (2005).

[2] Nakade, M., Kameyama, K., Ogawa, M., J. Mater. Sci. 39, 4131, (2004).

[3] Mark, J. E., Pan, S. -J., Makromol. Chemie: Rapid Comm. 3, 681, (1982); Mark, J. E., Jiang, C. -Y., Tang, M. -Y., Macromolecules, 17, 2613, (1984); McCarthy, D. W., Mark, J. E., Clarson, S. J., J. Polym. Sic.: Part B: Polym. Phys. Ed. 36, 1191, (1998).

[4] Iler, R. K., "The Chemistry of Silica", John Wiley and Sons, New York, 1979.

[5] Pelrine, R., Kornbluh, R., Pei, Q., Joseph, J., Science, 287, 836-839, (2000); b) O’Halloran, A., O’Malley, F., McHugh, P., J. Appl. Phys. 104, 071101-10, (2008); c) Perline, R. E., Kornbluh, R. D., Joseph, J. P., Sens. Actuat. A, 64, 77-85, (1998); d) Brochu, P., Pei, Q., Macromol. Rapid Comm. 31, 10-36, (2010).

[6] a) Pelrine, R., Kornbluh, R., Eckerle, J., Jeuck, P., Oh, S., Pei, Q., Stanford, S., Proc. SPIE, 4329, 148-156, (2001); b) Carpi, F., De Rossi, D., Kornbluh, R., Perline, R., Sommer-Larsen, P., Dielectric elastomers as electromechanical transducers, Elsevier, (2008); c) Prahlad, H., Kornbluh, R., Perline, R., Stanford, S., Eckerle, J., Oh, S., Proc. ISSS, SA-100, (2005); d) Koh, S. J. A., Zhao, X., Suo, Z., Appl. Phys. Lett. 94, 262902, (2009).

[7] Molberg, M., Crespy, D., Rupper, P., Nüesch, F., Månson, J.-A. E., Löwe, C., Opris, D. M., "High breakdown field dielectric elastomer actuators using encapsulated polyaniline as high dielectric constant filler", Adv. Funct. Mater. 20, 3280-3291, (2010).

[8] Gent, A. "Strength of Elastomers" in "Science and Technology of Rubber "N. Mark, J. E.; Erman, B. \& Eirich, F. R. (ed.) Elsevier, 455-495, (2005). 